\title{
El principio de interpretación conforme a los derechos humanos en dos sentencias: filiación homoparental y matrimonio igualitario
}

\author{
Recibido: 27 de agosto de 2020 • Aprobado: 28 de septiembre de 2020 \\ https://doi.org/10.22395/ojum.v20n42a10
}

\author{
Víctor Araya Madariaga \\ Universidad de Talca, Santiago, Chile \\ varayam@gmail.com \\ https://orcid.org/0000-0002-3731-5511
}

\section{RESUMEN}

El derecho constitucional actual ha desarrollado técnicas de interpretación que le son propias para evitar el uso de herramientas hermenéuticas provenientes de la interpretación legal, las cuales son inadecuadas para resolver conflictos en que están involucrados derechos humanos. Entre estas herramientas de interpretación se encuentra el principio de interpretación conforme a los derechos humanos. El objetivo del presente artículo es verificar su aplicación en la jurisprudencia chilena. Nuestra hipótesis es que no siempre es aplicado cada vez que se requiere, lo que genera soluciones diferentes cuando es invocado respecto de aquellas veces en que se omite. Utilizando el método dogmático y el método de casos a partir de dos sentencias, se analiza su implementación práctica. Concluimos que una de ellas lo aplica correctamente, mientras que la segunda lo omite al arribar a una sentencia diferente de la que se hubiese dictado al considerar el principio. pero ambas debieron acoger la solicitud de quienes solicitaron intervención judicial. En este sentido, sostenemos que una modificación constitucional permitiría hacer vinculante su aplicación en todo caso.

Palabras clave: derechos humanos; interpretación conforme; filiación homoparental; matrimonio igualitario; derecho constitucional. 


\title{
The Principle of Conforming Interpretation to Human Rights in Two Sentences: Homo-parental Filiation and Same-sex Marriage
}

\begin{abstract}
Current Constitutional Law has developed its interpretation techniques to avoid the hermeneutic tools from the legal interpretation, which are inadequate for solving conflicts related to Human Rights. The principle of conforming interpretation is among these tools. The objective of this article is to verify its application in Chilean jurisprudence. This research hypothesizes that it is not applied every time it is required, which results in different solutions every time it is invoked in comparison to those in which it is not. By employing the dogmatic and the case method through two legal sentences, this study analyzes its practical implementation. The study concludes that one of them applies it properly, while the second one omits it by sentencing something different than what would have been sentenced if the principle was considered, nonetheless, both sentences had to embrace the request of those who requested judicial intervention. Thus, the article states that a constitutional modification might allow a binding application for all cases.
\end{abstract}

Keywords: human rights; conforming interpretation; homo-parental filiation; samesex marriage; constitutional right. 


\section{INTRODUCCIÓN}

El presente trabajo proviene de la actividad académica realizada en el contexto de la asignatura Interpretación Constitucional de la maestría en Derecho Constitucional del Cecoch, Chile, en la que el autor se encuentra iniciando una línea de investigación en derechos humanos. El autor agradece a los revisores del artículo por sus valiosos comentarios que ayudaron a enriquecer el texto. Agradece además, muy sentidamente, las lecturas, comentarios y aportes del Dr. Gonzalo Aguilar Cavallo. Los posibles errores u omisiones son responsabilidad del autor.

En la sentencia Rol 7774-2019 (2020), el Tribunal Constitucional desestimó un recurso de inaplicabilidad por inconstitucionalidad presentado por una pareja del mismo sexo casada en España, cuya intención era inscribir dicho vínculo en Chile como matrimonio y no como acuerdo de unión civil, única solución para el caso que permite la Ley 20.830 (2015). En otra sentencia (Rol C-XXXX-20XX, 2020), esta vez del Segundo Juzgado de Familia de Santiago, una mujer dedujo demanda de reclamación de filiación en contra de su conviviente civil del mismo sexo, la cual fue finalmente acogida por la magistrada a cargo. Lo que pretendemos rescatar de estas sentencias es que ambas aluden a instrumentos internacionales de derechos humanos y a sentencias de tribunales extranjeros, pero los interpretan de manera aparentemente contraria.

Este trabajo pretende examinar el principio de interpretación conforme a los derechos humanos y justificar su necesaria aplicación en conflictos jurídicos que versan sobre dicha materia. Nuestra hipótesis es que el principio de interpretación conforme es central para la resolución de conflictos de derechos humanos y, de haberlo utilizado adecuadamente, ambas sentencias debieron acoger los argumentos de las partes que requirieron la intervención judicial. Por tanto, el objetivo de este trabajo es señalar las características del principio y la utilidad que presenta para resolver situaciones de conflicto de derechos humanos.

Se usará el método de casos. Se analizará dos sentencias y, a partir de ellas, se extraerán conclusiones de carácter general. Respecto de los fallos, el análisis se concentrará en las argumentaciones relacionadas con el derecho internacional. No se pretende comentar cada uno de los argumentos, sino el criterio interpretativo.

Este artículo se divide en dos grandes partes. La primera parte reseña brevemente las sentencias y los fundamentos que aluden a instrumentos internacionales de derechos humanos como marco interpretativo. La segunda parte examina la doctrina en el contexto principalmente americano en torno al principio de interpretación conforme, en el que se señala el concepto y las clasificaciones del mismo. 


\section{FILIACIÓN HOMOPARENTAL Y MATRIMONIO HOMOSEXUAL EN DOS SENTENCIAS RECIENTES}

La primera sentencia (Rol 7714-2019, 2020) recae sobre acción de inaplicabilidad. Esta fue dictada por el Tribunal Constitucional a inicios de junio de 2020. La segunda (Rol C-XXXX-20XX, 2020), pronunciada por un Tribunal de Familia, fue dictada con una diferencia de cuatro días. A continuación analizaremos, en este mismo orden, las dos sentencias mencionadas.

\subsection{El Tribunal Constitucional y el matrimonio homosexual}

En fallo de causa Rol 7774-2019 (2020) (Vera con Servicio de Registro Civil), de fecha 04 de junio de 2020, el Tribunal Constitucional (TC) desestimó la pretensión de las requirentes que perseguía hacer inaplicables ciertas disposiciones que, en su opinión, vulneraban preceptos de la Constitución Política de la República [CPR] (2005).

Las requirentes son una pareja del mismo sexo que contrajeron matrimonio en España el año 2012 y residen actualmente en Chile. Interpusieron un recurso de protección el 30 de octubre de 2019 frente al acto que consideran arbitrario e ilegal: la negativa del Servicio de Registro Civil e Identificación de inscribir su vínculo contraído en el extranjero como matrimonio y procedieron a registrarlo como acuerdo de unión civil (AUC). Pendiente esta gestión judicial, presentaron una acción de inaplicabilidad respecto del inciso final del artículo 12 de la Ley 20.830 (2015) que crea el AUC al señalar: "Los matrimonios celebrados en el extranjero por personas del mismo sexo serán reconocidos en Chile como acuerdos de unión civil". Asimismo, el inciso primero del artículo 80 de la Ley 19.947 (2004) establece la nueva ley de matrimonio civil (LMC), que indica: "el matrimonio celebrado en país extranjero, en conformidad con las leyes del mismo país, producirá en Chile los mismos efectos que si se hubiere celebrado en territorio chileno, siempre que se trate de la unión entre un hombre y una mujer". Ambos artículos imposibilitan la inscripción de su unión como matrimonio en Chile. Señalan como afectadas la protección de la familia matrimonial (CPR, 2005, arts. 1 y 19 n. ${ }^{\circ}$ 4), la prohibición de la discriminación arbitraria (CPR, 2005, art. 19 n. ${ }^{\circ}$ ), derecho a la identidad de su hijo en común (CPR, 2005, art. 1) y el interés superior del niño (CPR, 2005, art. 5, inc. 2). El TC resuelve en la sentencia (Rol 7714-2019, 2020) rechazar por seis votos en contra y cuatro a favor. Conviene precisar que se describe solo la argumentación de la resolución del caso. No se extendió el presente trabajo a las disidencias ni a las prevenciones

En primer término, se refiere al concepto de familia. Luego de indicar que el constituyente no la define, señala que habida consideración del momento de generación de la normativa, puede colegirse que se refiere a la familia tradicional conformada por mujer, marido e hijos (Rol 7774-2019, 2020, considerando 10). Luego cita el artículo 17 de la Convención Americana sobre Derechos Humanos (OEA, 1969), también conocida como Pacto de San José de Costa Rica (CADH), respecto al derecho a contraer 
matrimonio y a que el derecho interno no afecte la prohibición de discriminación. Alude, además, a la Corte Constitucional de Italia que en Sentencia Rol 138 (2010) señala que habiendo regulación legal del matrimonio, el contenido del precepto no puede reinterpretarse creativamente, argumento que el TC hace propio. Así concluye que familia, en el ordenamiento vigente, es aquella conformada por la unión afectiva de hombre, mujer e hijos, determinada además por "normas de orden público familiar claras y precisas" (Rol 7774-2019, 2020, considerando 12).

Sobre el matrimonio, comienza citando legislación interna en orden a señalar que es entre hombre y mujer. Luego alude a la Sentencia 132 (2018) de la Corte Europea de Derechos Humanos (Corte EDH) para argumentar que es competencia del legislador evaluar la validez del matrimonio contraído en el extranjero. Sostiene que el estatuto del AUC es suficiente para resguardar los derechos y obligaciones de las requirentes.

Respecto de la discriminación, señala que si se acepta que los preceptos legales impugnados discriminan arbitrariamente por su orientación sexual, ello afectaría el "orden público matrimonial, cuyas reglas son esenciales y obligatorias" (Rol 7774-2019, 2020, considerando 23). Para ello, cita en apoyo de su postura nuevamente a la Corte EDH (Rol 7774-2019, 2020, considerando 29). Sobre la vulneración a la Convención de los Derechos del Niño (CDN) y la afectación de la identidad del menor, no observa inconveniente. El sistema de filiación no permitiría, por lo demás, dos madres, sino padre y madre (Rol 7774-2019, 2020, considerando 29).

Finalmente, concluye que "las disposiciones legales censuradas en el requerimiento de estos autos constitucionales pertenecen al orden público matrimonial, y por consiguiente no presentan aspectos constitucionales que reparar. A quien corresponde corregirlos, si así se estimare procedente, es a los órganos colegisladores, llamados a fijar las reglas acerca del matrimonio civil" (Rol 7774-2019, 2020).

\subsection{El Segundo Juzgado de Familia de Santiago y la filiación homoparental}

En sentencia (Rol C-XXXX-20XX, 2020), de fecha 08 de junio de 2020, el Segundo Juzgado de Familia de Santiago resolvió una demanda de reclamación de filiación presentada por la madre un menor, en contra de su conviviente civil del mismo sexo (filiación homoparental). La acción tenía por objeto obtener que el Juzgado ordenara la inscripción de su conviviente civil, también como madre del menor. Suscribieron AUC en el año 2015 y tienen un hijo menor de edad que posee filiación solo con respecto a una de ellas, lo que vulnera, en su opinión, el interés superior del niño, su derecho a la identidad, su derecho a la vida familiar, la igualdad ante la ley y la integridad física y psíquica.

Así, luego de relatar la prueba rendida en el considerando noveno, da por asentados ciertos hechos y se pregunta: "ies eso una familia?". A continuación argumenta, citando el artículo 23 del Pacto Internacional de Derechos Civiles y Políticos [Pidcp] 
(1966), el artículo 17.1 de la CADH (1969), la Opinión Consultiva OC-21 (2014) de la Corte IDH, preceptos de los que deduce que el concepto de familia no está en caso alguno restringido solamente a la familia encabezada por una pareja heterosexual. En el derecho interno acude al concepto de familia de la Ley 20.530 (2011), que la reconoce como núcleo fundamental de la sociedad y sustentada en relaciones de afecto o de parentesco, sin restringirla a la pareja heterosexual como base, así como al mensaje de la Ley 20.830 (2015) que pretende proteger "otros grupos familiares" distintos del matrimonial. Sin embargo, esta ley no reguló la filiación en parejas del mismo sexo, como continúa la sentencia. Señala, entonces, que el Estado debe proteger, sin distinción, las diversas formas de familia que existan y facilitar la participación en la vida nacional. Agrega que, en tal sentido, es esencial que la filiación de un menor debe corresponder con su estado civil y su documento de identidad (Sentencia rol C-XXXX-20XX, 2020, considerando 9)

A continuación establece que el artículo 182 del Código Civil [CC] (2000) señala que son padres del niño quienes se someten a técnicas de reproducción asistida, lo que deviene una excepción al principio de la primacía del criterio biológico para determinar la filiación; la filiación legal puede ser distinta de la genética o biológica, pero que prima sobre ella. Así, la ley determina la filiación aun cuando en ese proceso ha habido una donación de gametos por parte de una tercera persona sin generar parentesco, al punto que quienes solicitan la reproducción asistida no pueden impugnar la filiación. Para solucionar el caso en que no es posible determinar quién es el padre o madre donante de gametos en el proceso de reproducción asistida, señala la sentencia que se debe acudir al derecho internacional y realizar una interpretación integradora de la Constitución. Solo de esta forma, agrega, puede darse protección efectiva a los derechos humanos de los afectados en este procedimiento. Este conjunto de fuentes que reconocen derechos fundamentales se denomina bloque de constitucionalidad.

Prosigue la sentencia señalando que este bloque de constitucionalidad está conformado para este caso, además de las normas de derecho interno, por jurisprudencia de la Corte Interamericana de Derechos Humanos (Corte IDH) en el artículo 8 de la Opinión Consultiva OC-24 (2017) que, en definitiva, le permite a la jueza

pronunciarse sobre la petición solicitada, en virtud de las normas sobre igualdad, el concepto de familia que subyace en nuestro ordenamiento jurídico, las convenciones internacionales sobre derechos humanos y su rango constitucional, y recurriendo a la norma de interpretación de los principios generales del derecho [...] este Tribunal dará lugar a lo solicitado (Opinión Consultiva OC-24, 2017, considerando 16)

\section{PRINCIPIO DE INTERPRETACIÓN CONFORME A LOS DERECHOS HUMANOS}

La evolución del derecho constitucional desde la Carta Magna hasta nuestros días lo ha autonomizado de otras ramas del derecho. Sin embargo, todavía la práctica 
de la interpretación y aplicación se ciñe a principios que son propios del derecho privado. ¿Los principios de Savigny son útiles como herramientas hermenéuticas para la solución de los conflictos de derechos humanos o son necesarias herramientas y principios autónomos del derecho constitucional y del DIDH? Proponemos una respuesta en los siguientes párrafos.

\subsection{Constitucionalismo contemporáneo, derechos humanos, internacionalización del derecho constitucional}

Desde el célebre fallo del caso Madison vs. Marbury de 1803 hasta las sentencias recién reseñadas, el desarrollo del derecho constitucional muestra notorios avances. El juez Marshall sienta las bases de la supremacía constitucional y del control de constitucionalidad en lo que puede considerarse el inicio del constitucionalismo contemporáneo (Carbonell, 2006, p. 298). En el siglo XX, los horrores del holocausto tuvieron como respuesta la Declaración Universal de los Derechos Humanos de 1948 y la Ley Fundamental de Bonn de 1949 que inician un período en que se intenta reconocer positivamente la preeminencia de la persona humana para el derecho y la protección irrestricta de su dignidad como fuente de los derechos humanos (Rolla, 2007, p. 46). Los derechos humanos (DDHH) son incorporados definitivamente a las constituciones posteriores al conflicto y se generan mecanismos de protección como el Sistema Europeo de Derechos Humanos y sus homólogos en América y África (Añaños, 2016, p. 263).

El concepto de dignidad humana introduce un contenido axiológico a la Constitución. El ordenamiento no solo debe adecuarse formalmente a ella, como analizó Marshall, sino también materialmente. En este sentido, observa Zagrebeslky (2008) que "Illa concepción material de la inconstitucionalidad libera el corazón de la constitución de la supremacía legislativa del Estado" (p. 259). La conformidad es de forma y fondo (Aldunate, 2009, p. 446).

Pero no solo eso. Estos sistemas de protección internacionales, materializados en pactos, son vinculantes para los estados que los suscriben, tanto en el cumplimiento de sus disposiciones como en el sometimiento que deben hacer a los órganos judiciales que crean. En consecuencia, tanto las normas de derecho interno como los órganos del estado deben adecuarse a estos instrumentos. Todo este mecanismo tiene un objetivo: respetar siempre y en todo momento la dignidad de la persona humana.

Esta internacionalización del derecho constitucional lo ha revestido de nuevas características, entre ellas, la apertura del derecho nacional al derecho internacional con diversas soluciones dependiendo de cada país. Esta tendencia comienza primero en Europa, después de finalizada la Segunda Guerra Mundial, en busca de herramientas efectivas para proteger a la persona más allá de las fronteras nacionales. Los acontecimientos de la primera mitad del siglo XX hicieron necesario el reconocimiento de DDHH como un estándar internacional, pero no solo eso, también se necesitó órganos de 
supervisión y control (Ferrer, 2011, p. 537). Además de los sistemas internacionales de protección de DDHH y sus respectivos tribunales, contribuyó también una creciente convicción al interior de los estados de la necesidad de respetar los acuerdos internacionales sobre la materia para garantizar su eficacia (Martínez, 2016, p. 148). Todo este desarrollo motivó la evolución y consolidación del derecho internacional de los derechos humanos (DIDH) como un fenómeno que, por cierto, es parte del proceso de globalización (Toro, 2005, p. 328).

Como señalábamos, los pactos de derechos humanos se hicieron cada vez más frecuentes, tanto a nivel mundial como regional. Esta internalización del derecho constitucional tiene una contracara en la constitucionalización del derecho internacional, que es incorporado al derecho interno de diversas formas, pero aplicado a través de la jurisprudencia constitucional. Una de las manifestaciones más claras de esto es otorgar jerarquía constitucional a los tratados internacionales de en materia de derechos humanos (TIDH) (Ferrer, 2011, p. 547). Este conjunto de principios y normas que se agregan al derecho interno requiere una solución interpretativa que ya no se satisface con las herramientas tradicionales del derecho común, pues aplicadas a estos casos suelen generar soluciones inapropiadas.

\subsubsection{Principios de interpretación propios del derecho constitucional}

El encabezado de este apartado contiene una premisa: el derecho constitucional tiene principios de interpretación que le son propios y distintos de los principios de interpretación legal (Aguilar, 2019, p. 89; Carbonell, 2013, p. 602). En lo formal, la Constitución comparte elementos con una ley, ambas son vinculantes y emanan de la soberanía del pueblo, la primera en virtud del poder constituyente y la segunda a través del parlamento. Sin embargo, su finalidad es un tanto distinta: a diferencia de la ley, que es de naturaleza abstracta y establece un supuesto normativo, un hecho subsumible y una consecuencia, la Constitución contiene además normas axiológicas y principios que son mandatos de optimización (Alexy, 2011, p. 12).

En lo material, la Constitución también se distingue de la ley. En la actualidad, en el constitucionalismo tiene fuerza una concepción sustancialista de la Constitución que, en palabras de Guastini (1999), es una "totalidad coherente y conexa de valores ético-políticos". Por tanto, recoge el conjunto de valores o "principios supremos' que la caracterizan y la distinguen de cualquier otra norma" (p. 173). Así las cosas, requiere principios de interpretación particulares. Al interpretar principios o derechos humanos podemos concluir entonces, junto con Martínez (2016), que "existe una interpretación constitucional de los derechos, no sólo formalmente, sino sustantivamente distinta a la interpretación legal" (2016, p. 131).

Ahora cabe precisar qué son los principios interpretativos. Hakansson (2009) señala: 
Los principios son aquellas instituciones que poseen cierta proyección normativa de las cuales se pueden obtener reglas jurídicas; no todos se encuentran en la Constitución, muchos se encuentran fuera de ella, pues se invocan, mueven y desarrollan mejor en un mundo de sentencias (p. 63)

Estos principios interpretativos son construcciones teóricas de la doctrina a partir de la observación de la práctica jurisprudencial. En lo tocante a interpretación del DIDH han sido especialmente influyentes las sentencias y opiniones de los órganos jurisdiccionales de los sistemas regionales de protección de los DDHH (Aguilar, 2019, p. 85).

Nos señala Häberle (2010, p. 406) que las primeras sistematizaciones de principios se desarrollaron en 1961, "convirtiéndose casi en un canon". Estos principios son i) principio de unidad de la constitución; ii) principio de concordancia práctica; iii) principio de interpretación conforme con la Constitución; iv) interpretación favorable a los derechos de la ley fundamental; v) principio de interpretación favorable a Europa y al derecho internacional; y vi) principio de interpretación constitucional del derecho comparado. Estos principios de interpretación, en los tres primeros casos son especialmente útiles para la interpretación constitucional en el derecho interno y pueden agruparse dentro de la interpretación sistemática. En los casos siguientes, aquellos que son conforme a derecho externo aluden fundamentalmente a DIDH.

Sin embargo, antes de explicar en qué consiste la interpretación conforme a los derechos humanos, conviene preguntarse por qué esta herramienta hermenéutica es necesaria. De allí arranca la vinculación entre el intérprete y las normas de DIDH tal que deba acudir a este principio interpretativo.

\subsubsection{Cláusula de apertura constitucional al derecho internacional}

Como hemos adelantado, el Estado constitucional contemporáneo tiene como punto de inicio y como medida de legitimación, la protección de la dignidad humana. En el Estado democrático actual, el sistema de protección de derechos fundamentales quedará cerrado tanto por el derecho interno como por el internacional (Bidart, 1998, p. 93). Para lograr este objetivo, las constituciones han desarrollado mecanismos de vinculación entre las normas internas y los TIDH. Caballero (2006) postula tres modelos de vinculación: uno que otorga preeminencia al derecho internacional, otro que propone una interpretación de DDFF conforme a los TIDH y un tercer modelo que es una combinación de ambos (p. 60).

Cualquiera sea el elegido, es la propia Constitución la que remite y vincula a los tribunales internos a interpretar los derechos humanos conforme a los TIDH (Santolaya, 2013, p. 488). Las normas que realizan esta vinculación se denominan doctrinariamente cláusulas interpretativas de apertura. Martínez (2016) las define como "aquellas que realizan un llamamiento a tratados internacionales y al derecho de la integración como criterios de interpretación para la aplicación de las propias cláusulas internacionales" (p. 148). 
De este modo, se configura un mínimo de derechos humanos protegidos por la Constitución, que además están en evolución por la constante interpretación que hace la Corte IDH (en el sistema americano). Es importante subrayar que esta apertura no es potestativa, sino que es una obligación para el intérprete de los derechos humanos (Santolaya, 2013, p. 449). Dependiendo del modelo de apertura elegido, se suscitará la controversia de la jerarquía que tendría la norma externa al incorporarse al derecho interno. La respuesta provendrá del constituyente en caso de que lo haya previsto, pues los TIDH no comprometen a los estados a asignarles una determinada jerarquía normativa. Esto se dice desde una perspectiva formal. Materialmente, y teniendo siempre presente el objetivo de otorgar el máximo de protección a la dignidad de la persona, podemos concluir que los TIDH tienen rango constitucional pues regulan la misma cosa que la Constitución: derechos humanos, su contenido y protección (Castillo, 2019, p. 31).

Algunas constituciones modernas como las de España (1978), Sudáfrica (1996), Colombia (1991) y México (reformada en 2011) contienen, además de la cláusula de apertura, una regla hermenéutica que hace vinculante la obligación de interpretar conforme al DIDH lo que ilustra una tendencia a positivizar dichas reglas. Como señala Saiz (2011, p. 24), se intenta que el intérprete constitucional utilice como herramienta hermenéutica el contenido de los TIDH con el objeto de regular de mejor forma los derechos constitucionales.

En Chile, la CPR (2005) contiene una cláusula de apertura agregada en la reforma constitucional de 1989, en el inciso 2 del artículo 5 que reconoce como límite a la soberanía los derechos humanos. Impone, además, el deber del Estado de promoverlos y respetarlos, no solo los contenidos en la propia Carta, sino también en los tratados internacionales ratificados y vigentes. Entre otros, se encuentra la CADH que además creó la Corte IDH, órgano jurisdiccional que supervigila el cumplimiento del tratado. En ese contexto desarrolla el control de convencionalidad que Aguilar (2016) define como:

la obligación que tendrían los Estados partes en la CADH, a través de todos sus órganos y especialmente sus jueces, de velar por el respeto y cumplimiento de las obligaciones convencionales que el Estado habría contraído y asumido al ratificar la CADH. (p. 133)

Así, el juez velará por los derechos establecidos en la CADH de forma activa y de oficio (Carbonell, 2013, p. 604). De esta forma, los derechos humanos gozan de protección en el ámbito interno y externo y materialmente el sistema queda cerrado al incorporar el DIDH al ordenamiento nacional (Bidart, 1998, p. 100). Ahora bien, no solo ingresan los preceptos de la $\mathrm{CADH}$, sino también las sentencias que ella dicta, así como sus opiniones consultivas (Castillo, 2019, p. 30).

En tal sentido, la Opinión Consultiva 05/1985 señaló que cuando a un mismo hecho le sean aplicables dos normas, se optará por las más favorable (citada en 
Ferrer, 2011, p. 532). Agrega Ferrer (2011, p. 532) que el estándar interamericano implica siempre optar por la norma más favorable, independiente de su fuente. De este modo, la interpretación conforme a los DDHH comienza a evidenciarse como un mecanismo eficiente de protección, pues el intérprete chileno debe acudir a los TIDH tanto por mandato de la Constitución (caso en que debe acudir a cualquier TIDH ratificado y vigente) como por ser signatario de la CADH (caso en que debe aplicar sus disposiciones, sentencias y opiniones consultivas, materializando el control de convencionalidad difuso).

En el mismo sentido comenta Rolla (2007, p. 20) que, como resultado de la integración de todas estas normas, se refuerza la garantía de los derechos constitucionalmente reconocidos, pues deben interpretarse principalmente en conformidad con la jurisprudencia de la Corte IDH y de la Corte EDH.

Por si queda alguna duda respecto a la obligatoriedad del control de convencionalidad que se materializa a través del principio de interpretación conforme a los DDHH, cabe recordar la sentencia de la Corte IDH en el caso Almonacid vs. Chile que señala en el párrafo 124 que el Poder Judicial debe considerar en su accionar la CADH y la interpretación que hace la Corte IDH respecto de ella; está obligado desde que el Estado ha ratificado el pacto (Almonacid Arellano y otros vs. Chile, 2008, párr. 124).

\subsection{Principio de interpretación conforme a los derechos humanos}

Hemos establecido ya que el derecho constitucional tiene principios de interpretación que le son propios. También hemos sostenido que la protección de los DDHH se logra vinculando derecho interno y DIDH. Al mismo tiempo, hemos afirmado que esta vinculación es obligatoria para el juez en materia de DDHH (y que, en el caso de la CADH, se denomina control de convencionalidad). Y, por último, hemos mantenido que la herramienta interpretativa para materializar esta vinculación es el principio de interpretación conforme a los DDHH. Resta por intentar una aproximación a su significado.

\subsubsection{Concepto de interpretación conforme a los derechos humanos}

Los derechos humanos pueden estar contenidos en diversas fuentes: tratados internacionales, declaraciones de derechos, derecho consuetudinario, normas de Ius Cogens, principios generales del derecho, la propia Constitución. En el concierto latinoamericano es de especial relevancia la $\mathrm{CADH}$, no porque sea una fuente exclusiva, sino porque está dotada de un órgano que hace exigibles sus normas y además las interpreta de forma vinculante para los estados parte del tratado. La primera aproximación a la interpretación conforme a los derechos humanos puede abordarse de acuerdo con los contenidos en la $\mathrm{CADH}$, aunque insistimos que no es la única fuente de ellos. Primeramente, conviene distinguir el control de convencionalidad del principio de interpretación conforme (en adelante Picdh), pues están muy vinculados. El control de convencionalidad apuntaría a expresar la siguiente cuestión de principio: frente a un 
conflicto de derechos humanos pueden resultar aplicables diferentes normas, unas de derecho interno y otras de DIDH. La aplicación de normas internas debe respetar los preceptos de la CADH y la interpretación que hace la Corte IDH de la misma, pues de lo contrario podrían dejarse sin aplicación a un caso concreto. Visto así, parece convertirse en un problema de jerarquía normativa. Con todo, es posible encontrar en la doctrina posiciones variopintas.

Para Henríquez (2014, p. 132), el control de convencionalidad puede explicarse de dos formas: como un control normativo o bien como un problema interpretativo. La primera de estas aproximaciones requiere constatar si las normas internas aplicadas a casos específicos se conforman a las interpretaciones que la Corte IDH hace de los DDHH. La herramienta para la operatividad de este ejercicio es el Picdh. Según la misma autora, la segunda explicación consiste en entender que el control de convencionalidad es un método hermenéutico que implica preferir la normativa internacional en tanto proteja de mejor forma los DDHH (Henríquez, 2014, p. 133).

El principio hermenéutico que en este caso permite efectuar el ejercicio es el principio pro homine o favor persona. Este principio tiene dos dimensiones o vertientes específicas, la primera como preferencia interpretativa y la segunda como preferencia normativa (Aguilar y Nogueira, 2016, p. 17), y sugiere en determinados casos inaplicar una norma interna cuya aplicación resulte contraria o menos protectora de los derechos humanos. La autora es crítica respecto de la primera aproximación pues se plantea un conflicto en el sistema de fuentes al admitir la posibilidad de inaplicar una norma (Henríquez, 2014, p. 135). Sin embargo, la misma solución puede obtenerse en el segundo caso ya que el principio favor persona tiene una vertiente normativa.

Por su parte, Aguilar (2019, p. 96) sostiene que el Picdh permite hacer control de convencionalidad y simultáneamente verifica el efecto irradiación y la eficacia horizontal indirecta de los derechos humanos. Lo entiende entonces como un ejercicio de adecuación del derecho interno con el DIDH contenido en diversos instrumentos. Distingue dos aristas o vertientes del principio: una formal y una material. La primera se relaciona con una interpretación en que es relevante la fuente formal y su ubicación en el sistema de normas. Se trata de una interpretación conforme a la Constitución y a los TIDH más propiamente. La segunda no se centra en el instrumento y su posición jerárquica, sino en el contenido. Dado que el objetivo es interpretar conforme a los $\mathrm{DDHH}$, la fuente de ellos puede estar en cualquier instrumento, incluso en el derecho consuetudinario o en el ius cogens. Lo importante es su contenido axiológico y, en tal sentido, esta arista representaría más genuinamente el Picdh.

En el mismo sentido, observa Ferrer (2011, p. 549) que la interpretación conforme es la técnica de interpretación en virtud de la que los derechos humanos pueden ser adecuados a valores, principios y normas recogidos en TIDH como el la jurisprudencia de sus tribunales. 
Para el autor la fuente de los derechos no es solo convencional (lo que restringiría a la interpretación conforme a los TIDH), sino que contempla otras fuentes internacionales. En estos casos se manifiesta con mayor claridad el Picdh. Observa Ferrer (2011) que las constituciones americanas que han adecuado sus textos a este principio (Bolivia, Colombia, Perú, México), han seguido el modelo del artículo 10.2 de la Constitución española que establece que los derechos fundamentales serán interpretados de conformidad con la Declaración Universal de Derechos Humanos y los TIDH ratificados. En lo pertinente, la alusión a la declaración universal materializa, a nuestro entender, el Picdh. Se supera así la discusión respecto a su carácter vinculante como instrumento jurídico. Este mismo modelo y apreciación puede efectuarse de acuerdo con Ferrer (2011) respecto a la Constitución de Portugal, pues contiene en su artículo 16.2 una disposición similar a la española. Agrega que en este ejercicio no pretende en principio privilegiar una norma externa frente a una interna, sino de armonizar la interpretación entre ellas, llegando incluso a admitirse la preferencia del derecho interno si es más protector de los derechos humanos que la norma de DIDH (Ferrer, 2011, p. 550).

Carbonell (2013, p. 604) señala por su parte que, en virtud del Picdh, las normas de DDHH se interpretarán conforme a la Carta Fundamental, pero también en conformidad a las TIDH. Sostiene que a través de este principio se construye una especie de bloque de constitucionalidad en virtud del cual se debe interpretar el ordenamiento jurídico mexicano. Agrega que, no obstante su positivización en la reforma constitucional de 2011, puede de todas formas inferirse a partir de la posición de la Constitución dentro del ordenamiento y de su fuerza vinculante (Carbonell, 2013, p. 605).

Siguiendo en el caso mexicano, Caballero (2011, p. 120) afirma que el principio de interpretación conforme incorporado en la Constitución se orienta a la conformidad con la CADH. La norma en comento señala que los DDHH se interpretarán en conformidad con la Constitución y los TIDH. Por tanto, restringe la interpretación al derecho convencional y excluye otras fuentes, al menos por esta vía. Agrega Caballero (2011, p. 120) que el objetivo de la cláusula es la expansión de los derechos y no solo resolver conflictos normativos o invalidar normas inconvencionales. Con todo, creemos que, al vincularse con la CADH por vía del artículo 29 c), es factible interpretar conforme a DDHH no contenidos en TIDH pero pertenecientes a normas de ius cogens, por ejemplo.

Observamos que la doctrina tiende a vincular el Picdh con el control de convencionalidad; en principio estamos de acuerdo, pero sostenemos que no se agota en esta fuente. Los derechos humanos están reconocidos en tratados, pero pueden provenir de distintas fuentes. Limitar el Picdh solo a la fuente convencional lo privaría de vincularse con el derecho consuetudinario, con los derechos implícitos o con el ius cogens. Coincidimos por lo tanto con la concepción de Ferrer (2011) ya expuesta, pues no restringe la fuente de los DDHH tan solo al derecho convencional. Estimamos 
que este mismo camino sigue nuestra Constitución en virtud de la cláusula de apertura que ya explicáramos anteriormente. Como señala el inciso 2 del artículo 5 , la soberanía tiene límite "en los derechos esenciales que emanan de la naturaleza humana" (CPR, 2005). Conviene precisar que no se trata de jerarquizar el DIDH por sobre la Constitución. Se trata de un proceso de contrastación de las normas y de armonizar el derecho internacional con el derecho interno en materia de derechos humanos. Así, incluso puede llegar a desecharse la aplicación del tratado por otorgar el derecho interno una mayor protección (Ferrer, 2011, p. 550).

\subsubsection{Tipos de interpretación conforme a los derechos humanos}

Como puede observarse, la interpretación sistemática tiene similitudes con la interpretación conforme. Hay entre ellas una relación de género a especie en opinión de Guastini (1999, p. 231). Siguiendo a este autor, es factible distinguir dos tipos de interpretación conforme.

La primera consiste en aquella interpretación que se conforma a una norma jerárquicamente superior. Así, si una norma admite interpretaciones opuestas y una de ellas es factible de conciliar su interpretación con la Constitución mientras en la segunda tal adecuación no es posible, habrá de preferirse la primera. Concluye Guastini (1999, p. 231) que el legislador es respetuoso con la ley fundamental. Esta clasificación no produce mayor duda. En caso de que un precepto legal sea contrario a una norma de un TIDH, cabe igual solución pues ya despejamos el problema de la jerarquía normativa.

El segundo tipo de interpretación conforme intenta adecuar una disposición a un principio general o fundamental del derecho. Se diferencia del anterior pues la diferencia de jerarquía entre los opuestos no es necesariamente formal, sino axiológica. Así, si una ley puede producir efectos retroactivos entendida de cierto modo y no retroactivos interpretada de otro, habrá de preferirse la segunda para adecuarse al principio de irretroactividad. En este sentido, Guastini (1999, p. 231) señala que el legislador es respetuoso con los principios generales del derecho. La clasificación de Guastini aplica a la interpretación conforme en general.

Una clasificación propia de la interpretación conforme a los DDHH es propuesta por Aguilar (2019). Señala que este principio presenta una vertiente formal y una material. La primera dice tener relación con la incorporación de normas al derecho interno. Sin embargo, es especialmente relevante la vertiente material, pues no se concentra en la jerarquía de las normas, sino en los valores, principios y derechos propiamente tales. De este modo el juez debe interpretar de acuerdo con principios y valores, independiente de la jerarquía de la norma externa. En este sentido, existe similitud con la clasificación propuesta por Guastini (1999), pero sugiere que la interpretación conforme a los DDHH se corresponde con la vertiente material, pues ambos tipos de interpretación podrían llevar a resultados contrapuestos: 
La vertiente formal de la interpretación conforme se entiende referida a una fuente formal, por ejemplo, un tratado o la Constitución. Por lo tanto, esta interpretación quedaría sometida a la jerarquía del instrumento conforme al cual se interprete el ordenamiento. Mientras que la vertiente material exigiría que la interpretación fuera conforme a los derechos, los valores y principios que trasuntan estas fuentes formales. Por lo tanto, esta interpretación no quedaría sujeta a ningún tipo de jerarquía formal, aunque quizás a un material, como por ejemplo, cuando el parámetro interpretativo se refiere a las denominadas normas de Ius Cogens. (Aguilar, 2019, p. 120)

Una tercera clasificación puede ser propuesta a partir de las características que señala Sáiz (2011) para la conformidad, dependiendo de si el TIDH al que se alude contempla un órgano jurisdiccional. Si no contempla órgano jurisdiccional, la conformidad puede, a su vez, volver a distinguirse: como mera compatibilidad o como conformidad en sentido estricto. La mera compatibilidad se da al interpretar de cualquier modo que no resulte contradictorio con el TIDH. La conformidad en sentido estricto se produce al otorgar un contenido al derecho deducible del texto del TIDH. Si contempla un órgano jurisdiccional que efectúa interpretación del contenido del tratado, la interpretación conforme deberá extenderse a las decisiones del órgano (Sáiz, 2011, p. 34).

\subsection{Aplicación del principio de interpretación conforme en sentencias comentadas}

Como señalamos al inicio, no se pretende comentar cada uno de los fallos completamente, sino el criterio interpretativo. En este punto, habiendo analizado las dos sentencias mencionadas, se puede apreciar una serie de similitudes y diferencias. Estas características, quizás, aumentan lo paradójico de la situación. Desde el punto de vista de las similitudes, ambas sentencias con las que se introdujo este texto comparten en la solución del caso alusiones al DIDH, particularmente a la CADH, y a la CDN. Se cita también algunas sentencias de tribunales europeos, fundamentalmente por parte del TC. Ambos casos corresponden a familias conformadas por parejas del mismo del mismo sexo con un hijo menor de edad.

En un caso, conocido por el TC se busca inaplicar normas en procedimiento de protección para obtener, en definitiva, la inscripción del matrimonio celebrado en España en el registro civil como matrimonio y no como AUC. En el otro caso se pretende la filiación del menor por la conviviente civil cuya inscripción como madre fue rechazada pues ya figura con filiación materna. Los dos casos plantean una problemática relacionada con derechos humanos. En el caso de inscripción de matrimonio, se argumenta en torno al significado de familia, al concepto legal de matrimonio y a la protección del interés superior del niño. El caso de la filiación también discurre sobre el concepto de familia e interés superior del niño. En ambos casos aparece clara la tensión generada por la conformación homosexual de la pareja y las normas legales que impiden la inscripción del matrimonio (legalmente entre hombre y mujer según resuelve el TC) y la filiación por dos personas del mismo sexo 
(padre y madre según señala la ley). Con todas estas similitudes, sin embargo, se concluye en sentidos diferentes.

En el punto 2.1.2 argumentamos con respecto a la obligatoriedad que tiene el juez de interpretar el alcance de los derechos humanos conforme a los TIDH ratificados y vigentes. Señalamos, además, que ello no es facultativo, sino un deber del juez que, a nuestro juicio, es mayor en el caso del TC. Veamos cómo se trasunta lo anterior en estos casos.

Respecto de la inaplicabilidad, y obviando ciertas consideraciones que hace la sentencia con respecto al artículo 102 del CC (2000) que más bien son de admisibilidad y no de fondo, parece claro que hay planteado un conflicto entre el derecho a no ser discriminado arbitrariamente, el derecho a contraer matrimonio, el derecho a formar una familia por una parte y la legislación nacional por otra. Creemos que la solución, esto es, determinar si en el caso concreto se produce una inconstitucionalidad (y no en abstracto como a nuestro entender razona el fallo), debe encontrarse acudiendo a los TIDH ratificados y vigentes. Ellos son la CADH y la CDN.

Sin embargo, se acude a la intención del constituyente en una interpretación originalista y a argumentaciones en el plano legal y de deficiencia legislativa. Incluso la argumentación obiter dictum que acude al derecho comparado parece inadecuada, pues no ayuda a interpretar los DDHH de forma tal que se maximice su alcance. Más bien, parece destinada a sustentar la vigencia del concepto legal de matrimonio entre hombre y mujer, cuestión que no es pertinente a nuestro juicio. No es el concepto legal de matrimonio lo impugnado, lo sometido a conocimiento del TC; es si la aplicación al caso concreto de ciertos preceptos legales (artículo 12 de la Ley 20.830 que crea el AUC e inciso primero del artículo 80 de la Ley 19.947) producen un resultado contrario a la Constitución. Entendemos que una aplicación correcta del principio de interpretación conforme a los DDHH habría generado que el fallo se argumentara en base a otros preceptos provenientes de los instrumentos ya mencionados. Ello no implica necesariamente un resultado distinto, pero sí una argumentación conforme a los derechos humanos.

La sentencia en materia de filiación, a nuestro juicio, entiende bien que el conflicto planteado es de derechos humanos y, por tal motivo, se extiende largamente en el DIDH aplicable. Acude a la CADH y a la CDN fundamentalmente. Independiente del fallo, destacamos lo que entendemos como una correcta interpretación de las normas que son aplicables mediante la utilización de la herramienta hermenéutica adecuada. La interpretación conforme está íntimamente ligada con otro principio, que es el principio pro homine. El Picdh permite su uso abiertamente al sentenciador, quien queda dotado de un conjunto de instrumentos jurídicos (CADH, CDN, entre otros) cuyos contenidos axiológicos y principios le permiten resolver el caso otorgando preeminencia a la protección de la dignidad humana, aunque ello implique inaplicar 
o reinterpretar ciertos preceptos legales que no atienden a los principios esbozados por Savigny, sino a criterios interpretativos acordes a los derechos humanos.

\section{CONCLUSIONES}

Ambos casos contienen, demás está decir, una fuerte connotación valórica. Con mayor razón creemos que se debe actuar cuidadosamente con las partes, pues no puede soslayarse que la protección de sus derechos humanos arranca justamente del respeto a la dignidad humana. En estos casos ventilados en tribunales existe un elemento afectivo que debe ser tenido en cuenta por el sentenciador; la familia, el matrimonio, la filiación de los hijos no son solo abstracciones jurídicas neutras, son normas que regulan algunos de los actos más importantes en la vida de una persona.

La procreación como objeto del matrimonio, por ejemplo (cuya discusión como argumento no es parte de este trabajo), no es solo un proceso biológico de cruzamiento entre individuos de la misma especie como parece sugerir una de las sentencias, es también parte fundamental del proyecto de vida en el sentido más profundo que pueda reconocerse. Estimamos que la interpretación conforme a los derechos humanos, teniendo siempre como guía el respeto de la dignidad humana, exige un cuidado especial en la redacción de la decisión. En este aspecto, la sentencia del Segundo Juzgado de Familia, independiente de la decisión tomada, nos parece muy acorde a lo expuesto.

Creemos que lo propuesto en este trabajo podría verse resuelto con una modificación normativa, ya sea en la Constitución al estilo de la reforma en México de 2011, que haga explícita la interpretación conforme al DIDH. Otro tanto puede conseguirse al prosperar los proyectos de ley que se tramitan en el congreso actualmente sobre filiación homoparental (boletín 10626-07) y sobre matrimonio igualitario (boletín 11422-07). Una u otra solución configuran una protección positiva a ambos derechos más allá de la solución interpretativa que planteamos. No obstante cabe preguntarse: ¿No es suficiente la ratificación por parte de nuestro país de TIDH vigentes y que ya protegen tales derechos?

Probablemente en el curso de los próximos meses se interpondrán más acciones similares a las comentadas, lo que generará una opinión jurisprudencial que podrá analizarse nuevamente a la luz del principio de interpretación conforme a los derechos humanos.

\section{REFERENCIAS}

Acción de Inaplicabilidad (2019, 13 de Noviembre). Tribunal Constitucional Rol 7.774-2019. https:// bit.ly/3umFwVE

Aguilar, G. (2016). Constitucionalismo global, control de convencionalidad y el derecho a huelga en Chile. Anuario Colombiano de Derecho Internacional, 9. 
Aguilar, G. (2019). El principio de interpretación conforme a los derechos fundamentales a la luz de la jurisprudencia chilena. Cuestiones Constitucionales: revista mexicana de derecho constitucional, (41), 83128. https://doi.org/10.22201/iij.24484881e.2019.41.13942

Aguilar, G., y Nogueira, H. (2016). El principio favor persona en el derecho internacional y en el derecho interno como regla de interpretación y de preferencia normativa. Revista de Derecho Público, (84), 13-43. https://revistaderechopublico.uchile.cl/index.php/RDPU/article/view/43057

Aldunate Lizana, E. (2009). La fuerza normativa de la constitución y el sistema de fuentes del derecho. Revista de derecho (Valparaíso), (32), 443-484. https://dx.doi.org/10.4067/S0718-68512009000100013

Alexy, R. (2011). Los derechos fundamentales y el principio de proporcionalidad. Revista española de derecho constitucional, 31(91), 11-29. https://bit.ly/37GJI8O

Añaños, K. (2016). Sistema Universal de Protección de Derechos Humanos: Análisis de los Informes del Comité de Derechos Humanos en Latinoamérica. Revista de paz y conflictos, 9(1), 261-278. https:// bit.ly/3pNDoma

Bidart, G. (1998). La interpretación de los derechos humanos en la jurisdicción internacional y en la jurisdicción interna. En V Congreso Iberoamericano de Derecho Constitucional (pp. 93-105). UNAM Instituto de Investigaciones Jurídicas. https://bit.ly/2ZEIA10

Caballero, J. (2006). El derecho internacional en la integración constitucional. Elementos para una hermenéutica de los derechos fundamentales. En M. Carbonell y D. Valadés (Eds.), El estado constitucional contemporáneo. Culturas y sistemas jurídicos comparados. UNAM - Instituto de Investigaciones Jurídicas.

Caballero, J. (2011). La cláusula de interpretación conforme y el principio pro persona (Artículo 1, segundo párrafo, de la Constitución). En M. Carbonell y P. Salazar (Eds.), La Reforma constitucional de derechos humanos: Un nuevo paradigma (pp. 103-133). UNAM - Instituto de Investigaciones Jurídicas.

Carbonell, M. (2006). Marbury versus Madison: En los orígenes de la supremacía constitucional y el control de la constitucionalidad. Marbury versus Madison: en los orígenes de la supremacía constitucional y el control de la constitucionalidad, 5, 289-300. https://bit.ly/3pSWbw]

Carbonell, M. (2013). La interpretación constitucional de los derechos fundamentales y el uso del derecho comparado en el diálogo jurisprudencial. En E. Ferrer Mac-Gregor y A. Herrera García (Eds.), Diálogo jurisprudencial en Derechos Humanos entre Tribunales Constitucionales y Cortes Internacionales: In memoriam Jorge Carpizo, generador incansable de diálogos. Tirant Lo Blanch México.

Castillo Córdova, L. (2019). La relación entre el derecho nacional y el derecho convencional como base del control de convencionalidad. Estudios constitucionales, 17(2), 15-52. https://dx.doi.org/10.4067/ S0718-52002019000200015.

Congreso de la República de Chile (2004, 7 de mayo). Ley 19.947. Establece nueva Ley de Matrimonio Civil. https://bit.ly/3kcssgR

Congreso de la República de Chile (2011, 6 de octubre). Ley 20.530. Crea el Ministerio de Desarrollo Social y Familia y modifica cuerpos legales que indica. http://bcn.cl/2j52x

Congreso de la República de Chile. (2015, 13 de abril). Ley 20.830. Crea el Acuerdo de Unión Civil. https://bit.ly/3dBsI7H

Corte Constitucional de Italia (2010, 14 de abril). Sentencia 138/2010 (Juicio de legitimidad constitucional por vía incidental). https://bit.ly/3pKZpC4 
Corte Europea de Derechos Humanos (2018, 14 de marzo). Sentencia 132/2018 (Orlandi y otros con Italia; solicitudes 26431/12; 26742/12; 44057/12 y 60088/12). https://bit.ly/3qOHBak

Corte Interamericana de Derechos Humanos (2006, 26 de septiembre). Sentencia Serie n. 154 (Almonacid Arellano y otros vs. Chile). https://bit.ly/3aLNdN6

Corte Interamericana de Derechos Humanos (2017, 24 de noviembre). Opinión Consultiva OC-24/17 (Opinión solicitada por la República de Costa Rica sobre identidad de género e Igualdad y no discriminación a parejas del mismo sexo). https://bit.ly/3aGYzC6

Ferrer, E. (2011). Interpretación conforme y control difuso de convencionalidad. El nuevo paradigma para el juez mexicano. Estudios constitucionales, 9(2), 531-622. https://bit.ly/3sfzRij

Guastini, R. (1999). Distinguiendo: estudios de teoría y metateoría del derecho. Gedisa Editorial.

Häberle, P. (2010). Métodos y principios de interpretación constitucional. Un catálogo de problemas. Revista de Derecho Constitucional Europeo, 13, 379-414. https://bit.ly/3kbMIPM

Hakansson Nieto, C. (2009). Los principios de interpretación y precedentes vinculantes en la jurisprudencia del Tribunal Constitucional Peruano. Una aproximación. Dikaion, 18, 55-77, https:// bit.ly/37VWVuT

Henríquez Viñas, M. L. (2015). La polisemia del control de convencionalidad interno. International Law. Revista Colombiana De Derecho Internacional, 12(24), 113-142. https://doi.org/10.11144/Javeriana. IL14-24.pcci

Martínez Dalmau, R. (2016). Problemas actuales sobre la interpretación constitucional de los derechos. Revista IUS, 10(37), 129-151. https://bit.ly/2ZH19V2

Ministerio de Justicia (2000, 16 de mayo). Decreto con Fuerza de Ley 1 de 2000. Fija texto refundido, coordinado y sistematizado del Código Civil. http://bcn.cl/2f6t3

Ministerio Secretaría General De La Presidencia. (2005, 17 de septiembre). Decreto 100 de 2.005. Fija el texto refundido, coordinado y sistematizado de la Constitución Política de la República de Chile. https://bit.ly/3pNda3g

Organización de Estado Americanos, OEA (1969, 22 de noviembre). Convención Americana sobre Derechos Humanos. https://bit.ly/2NTOk4k

Organización de Naciones Unidas, ONU (1966, 16 de diciembre). Pacto Internacional de Derechos Civiles y Políticos. https://bit.ly/3kdCNck

Recurso de Protección (2019, 30 de octubre). Corte de Apelaciones de Santiago Rol 164.844-2019 (Vera con Registro Civil e Identificación). https://bit.ly/2ZCJtHF

Rolla, G. (2007). Técnicas de garantía y cláusulas de interpretación de los derechos fundamentales. Consideraciones sobre las constituciones de América latina y de la Unión Europea. Panóptica, $8,3-47$.

Sáiz, A. (2011). La interpretación de los derechos fundamentales de conformidad con el derecho internacional de los derechos humanos. Hendu - Revista Latino-Americana de Direitos Humanos, 2(1), 20-42. http://dx.doi.org/10.18542/hendu.v2il.664

Santolaya, P. (2013). La apertura de las Constituciones a su interpretación conforme a los tratados internacionales. En E. Ferrer Mac-Gregor y A. Herrera García (Eds.), Diálogo jurisprudencial en Derechos 
Humanos entre Tribunales Constitucionales y Cortes Internacionales: In memoriam Jorge Carpizo, generador incansable de diálogos. Tirant Lo Blanch México.

Segundo Juzgado de Familia de Santiago (2020, 8 de junio). Sentencia Rol C-XXXX-20XX (Reclamación de Filiación). https://bit.ly/3qKjtWG

Toro Huerta, M. I. (2005). La apertura constitucional al derecho internacional de los derechos humanos en la era de la mundialización y sus consecuencias en la práctica judicial. Boletín mexicano de derecho comparado, 38(112), 325-363. https://bit.ly/2RmQxah

Tribunal Constitucional (2020, 4 de junio). Sentencia Rol 7774-2019 (Requerimiento de Inaplicabilidad respecto del artículo 12, inciso final, de la Ley 20.830 y de la frase "siempre que se trate de la unión entre un hombre y una mujer" contenida en el artículo 80, inciso primero, de la Ley 19.947). https://bit.ly/3qJRk20

Zagrebelsky, G. (2008). El juez constitucional en el siglo XXI. Revista Iberoamericana de Derecho Procesal Constitucional, 10, 249-268. https://bit.ly/3qMLU6f 